\title{
Swearword strength in subtitled and dubbed films: a reception study
}

\begin{abstract}
In this paper we present the results of the first empirical reception study on the comparative strength of swearwords in two audiovisual translation (AVT) modes. We test the assumption/hypothesis that swearwords are perceived as stronger in writing (i.e. subtitles) than in spoken language (i.e. dubbing), which has led to the long-held translation practice of toning down or deleting swearwords more in subtitles than in dubbing. By means of an online survey, participants were asked to a) rate the psychological distance between the connotative meanings of swearwords embedded in ten film clips on a four-point strength scale, and b) comment on their ratings in open-ended text boxes. The results of various types of quantitative analysis show that our participants do not rate swearwords in subtitles higher than in dubbed clips. The qualitative analysis identified contextual factors (genre/director of film, participating characters and their relationship, setting and linguistic context) as well as viewer characteristics (gender, swearing habits and reactions to swearing) as main determinants of swearword strength. The convention of toning down or deleting swearwords more in subtitles than in dubbed audiovisual products thus seems to be based on an invalid assumption and ought to be abandoned altogether.
\end{abstract}

Keywords: swearing, reception study, translation practices, subtitling, dubbing

\section{Introduction}

[...] through comparisons of subtitles and dubs of the same products, it would appear that subtitles reduce taboo language more than dubbing (Bucaria 2007), presumably because of the belief that these words in writing have a stronger effect than speech (Roffe 1995), but again, this is still to be proven empirically (Chiaro 2009: 151).

The idea that swearing is more offensive in writing than in spoken language has been perpetuated for centuries (Carstensen 2012; Chiaro 2009; Roffe 1995), but has not been tested empirically yet. ${ }^{1}$ The similar claim, that swearwords have a stronger effect in subtitling than in dubbing, has resulted in the AVT practice of toning down or omitting swearwords more in subtitled versions of audiovisual products than in dubbed ones (e.g. Díaz Cintas and Remael, 2007; Gottlieb 1994; Ivarsson and Carrol 1998). We thus lack knowledge whether audiences

\footnotetext{
${ }^{1}$ A thorough literature search yielded no results; four main authors in the field, Timothy Jay, Kirsty Beers Fägersten, Tony McEnery and Magnus Ljung, confirmed this in personal communication [22/11/18].
} 
really find swearing in the subtitled version of the same films more offensive than in their dubbed counterparts. If it can be shown that viewers do not find swearwords more offensive in subtitled than in dubbed audiovisual products, the translation practice of softening or omitting swearwords in subtitles needs to be revisited.

The research question this paper seeks to answer is whether audiences find swearing in subtitles more offensive than in dubbed AVT products. More specifically, we will test the hypothesis that swearwords are perceived as stronger in writing/subtitles than in spoken language/dubbing. Swearword strength, however, does not only depend on language mode. Other factors such as genre, a person's gender, age, native-speaker status, swearing habits and reaction to swearing have been shown to impact on the perceived offensiveness of swearing in previous research (see Section 2). We therefore also ask: do these variables impact significantly on the perceived strength of swearwords? Other contextual variables, such as setting, participating characters and their relationship and linguistic context, will be explored qualitatively.

This paper is structured as follows. In Section 2 we review the literature on swearing and swearing in AVT with emphasis on the differences between subtitling and dubbing. Section 3 introduces the corpus material and survey participants, and outlines the research methodology. In Section 4 we present the results of the survey and their analysis, and discuss their implications for AVT.

\section{Swearing and swearing in (audiovisual) translation}

Swearing is not only a hotly debated topic among the public and in the media, but also subject of scientific research in several disciplines (e.g. Allan and Burridge 2006; Andersson and Trudgill 1990; Beers Fägersten 2012; Ljung 2009, 2011; McEnery 2006; Pinker 2007 in linguistics; Fernández Dobao 2006; Fernández Fernández 2009; Han and Wang 2014; Hjort 2009 in translation studies, and Jay 1977, 1992, 2000, 2009; Jay and Janschewitz 2008; van Lancker and Cummings 1999 in psychology). Swearing attracts all this attention by virtue of its taboo nature and potential for offence. These characteristics enable swearwords to take on specific linguistic, psychological, social and interpersonal functions.

Hence, a functional definition of swearing which includes taboo subjects, emotions and non-literal meanings is required. To qualify as swearing, a word or expression should be 
offensive, at least to some people in certain situations. To be offensive, swearing needs to target something that is prohibited or restricted by social or religious custom, i.e. taboos (Andersson and Trudgill 1990: 50; Ljung 2011: 4; Pinker 2006). Taboo topics violated in swearing fall into a few major groups: religious, scatological, sexual, and insulting to (especially female) family members (Ljung 2011: 35). Because swearwords can be more or less offensive, they can be ranked in order of strength.

Psycholinguistic studies have used word scaling and autonomous arousal paradigms ${ }^{2}$ to establish that swearwords range from mildly offensive (e.g. damn, fart, crap, hell, idiot) to moderately offensive (e.g. bastard, goddamn, piss) to very offensive (e.g. cunt, fuck, cocksucker) (Janschewitz 2008; Jay 1992; Jay et al. 2008). In a recent report the British Office of Communications (Ofcom 2016) has investigated attitudes to potentially offensive language (and gestures) on TV and radio, and categorised 150 English swearwords into mild, medium and strong.

Yet what is offensive cannot be universally construed. Judgments of offensiveness depend on the propositional content of swearwords, regardless of their literal meaning, and on a sense of what is appropriate in a particular situation. The ultimate offensiveness of swearwords is thus not only determined by the particular words/expressions used, or the tone of voice with which they are uttered, but is influenced by contextual variables such as the speaker-listener relationship (including gender, age and status), the social-physical setting (including public vs. private, formal vs. informal) and linguistic/cultural experience (native vs. non-native speaker, familiar vs. unfamiliar with the culture) (Allan and Burridge 2006; Fernández Fernández 2009; Filmer 2012; Jay and Janschewitz 2008).

In addition to focusing on taboos, swearing should also constitute emotive language use according to most definitions (Pinker 2007). Its main function for the speaker is to convey positive (e.g. happy) or negative (e.g. angry, frightened, frustrated) feelings or attitudes. Swearing can be a mechanism for tension release (“annoyance swearing”, Montagu 2001: 88) and negatively charged. In other contexts, such as in-group slang, jokes, self-deprecation or ironic sarcasm, swearwords can promote social harmony and cohesion, especially when produced with an appropriate tone of voice, and thus achieve positive social outcomes ("social swearing", Montagu 2001: 88). Swearing can also occur in situations that are neither

\footnotetext{
${ }^{2}$ Scaling studies rate the psychological distance between the connotative meanings of words, e.g. strong vs. weak, on a semantic differential scale (a derivation of the Likert scale). Autonomic arousal studies measure heart rate or galvanic skin response to evaluate more unconscious psychological processes such as arousal while processing swearwords.
} 
saliently positive nor negative (Harris et al. 2003: 4). Pinker (2007: 357) ties the three main characteristics of swearing together in one succinct statement: "taboo status itself gives a [swear]word an emotional zing, regardless of its actual referent".

Other linguistic characteristics of swearwords/expressions are, they are frequently employed in a non-literal sense (Andersson and Trudgill 1990; Ljung 2011: 4), commonly associated with "low" or vernacular register ranges, often formulaic ${ }^{3}$ and subject to lexical and syntactic constraints (Ljung 2011: 4). These main characteristics of swearwords all have consequences for the translation of swearing.

Because swearwords are mostly used non-literally, source language (SL) ${ }^{4}$ swearwords can be replaced with connotatively - but not necessarily semantically - similar ones from the target language (TL). Fuck, for example, can be replaced with shit in many contexts and still express annoyance, contempt or impatience (Fernández Dobao 2006). Thus, while translators can "play" with the literal meaning of the TL expression, it should retain the expressive function, tone and register of the SL original and be sensitive to the sociocultural context in which it is used (Fernández Fernández 2009). Omitting swearwords in translation can thus create a more formal, self-censored TL text that differs from the original and lacks accuracy (Gambier 2018: 60; Soler Pardo 2015: 159).

Swearing is furthermore culture-specific because different social groups have different taboo topics (Fernández Dobao 2006; Wan and Hang 2014). These differences are reflected in the semantic fields swearwords come from in individual languages (Andersson and Trudgill 1990: 53). Scatological terms, for example, clearly dominate in German swearing (Nübling and Vogel 2004); sexual ones, which are prominent in English, are rarely used in German (Gauger 2012; Ljung 2011: 39). Overall, however, Ljung (2011: 1) concludes that, apart from the range and frequency of swearwords varying from one language to another, swearing is a "linguistic resource whose functions and realizations across languages are remarkably similar and seem to emanate from a common pool of emotive utterance types".

Emotive expressions, such as automatic responses to pain, surprise, happiness frustration, are non-propositional; propositional swearing, on the other hand, is intentional and done creatively, often for highly strategic purposes (Jay 2000, 2008). As we are dealing with

\footnotetext{
${ }^{3}$ Due to the formulaic nature of swearing, we treat single and compound swearwords and (pre-/post-)modified swearing expressions alike in this study.

${ }^{4}$ Source language: the language of the source text; target language: the language the text is translated into.
} 
scripted audiovisual products and their translations, swearing is always propositional in our data. If swearing is propositional in film scripts, why is it used and what is it used for?

One reason why swearwords are used in film scripts is that swearing is part of everyday human communicative behaviour. The inclusion of swearwords in AV scripts thus contributes to the "naturalness" of the text. In addition to conveying positive and negative feelings and attitudes, other main functions of swearing are to add emphasis to speech (Ljung 2011: 4), to intensify emotional communication (Jay 2009: 155), to shock and display power (Allan and Burridge 2006), and to mark a character's identity.

Swearing can be used for characterization in film scripts because it is individual. Corpus-linguistic studies of swearing (McEnery 2006; Mehl and Pennebaker 2003) have found substantial individual differences in swearing rates per speaker. Swearwords depend on gender, age, group identity and personality factors, and thus lend themselves to characterization in audiovisual products. Nowadays men and women swear at roughly the same rate (Jay and Janschewitz 2008: 272; McEnery 2006), but men tend to use stronger and more offensive language than women, especially in same-sex interactions (Allan and Burridge 2006). Swearing rates peak in teenage years and decline as speakers become more conservative with age (Holmes 2013; Jay and Janschewitz 2008: 272; McEnery 2006: 45). Furthermore, non-native speakers have been found to be less sensitive than native speakers to the influence of contextual variables in swearing scenarios (Jay and Janschewitz 2008: 283285). This is important for a reception study of swearing in AVT, and particularly applies to subtitling. In this translation mode, viewers who recognise swearwords on the soundtrack will notice changes in register such as toned down swearwords (Sánchez 2004), which impact on their viewing experience.

The main aim of this paper is to establish whether swearwords are perceived as stronger in subtitles than in dubs. But why should swearing in subtitling be more offensive than swearing in dubbing? The main reason given in the literature (e.g. Carstensen 2012; Chiaro 2009; Roffe 1995) is the difference in language modes: subtitles are written and dubbing is spoken, and written language tends to be more formal than spoken language. Another reason given in the literature is frequency of occurrence (McEnery 2006); swearwords seem stronger in written texts because they are less frequent in written than in spoken language. 
We found no studies that compare the offensiveness of swearwords in the written and spoken modes, and only one which compares the frequency of swearwords in spoken and written language. A corpus linguistic investigation of fuck in the British National Corpus (BNC) by McEnery and Xiao (2004) revealed that this swearword occurs 12 times more frequently in spoken than in written language $(\mathrm{p}<0.001)$. Because of the scarcity of literature on this issue, we ran searches on the two most frequent swearwords according to Jay (2009: 156), fuck and shit, also on the BNC. Fuck has a frequency rate of 5.78 instances per million words in the spoken section of the BNC and 7.42 in the written section. Shit has a frequency of 7.0 instances per million words in the spoken and 10.88 in the written BNC. The most frequent swearwords are thus indeed less common in written than in spoken language. However, the argument that swearwords are perceived as stronger in subtitled than in dubbed AVT products because of the differences in language modes remains problematic: subtitles appear in writing on the screen, but viewers know that they represent spoken language. Audiences should therefore expect more informal language, including swearwords, in subtitles (see Hjort 2009 for a similar argument).

Despite the lack of empirical support for, and flawed arguments in support of the assumption that swearing is more offensive in subtitling than in dubbing, omitting and toning down swearwords in subtitles has long been common translation practice. The convention is reiterated - and even recommended - in many teaching and research publications on subtitling, not in the context of temporal-spatial constraints on subtitling, but because swearwords are assumed to be perceived as stronger in writing (Díaz Cintas and Remael 2007; Díaz Cintas and Andermann 2009; Díaz Cintas and Neves 2015; Ivarsson and Carroll 1998). Díaz Cintas and Remael, however, also caution against overdoing this practice, because swearwords (and "bad" language in general) frequently form part of the idiosyncratic or group register of on-screen characters (cf. Soler Pardo 2015). Deleting such expressions or softening them thus modifies characterisation for the target audience. Ivarsson and Carroll (1998) and Gambier (2018) stress that it is not the translator's role to censor a film, unless specifically asked to do so by the client, as directors often choose to include such language for artistic reasons. Hjort (2009), however, has shown that subtitlers sometimes receive explicit instructions (from their employers or clients) to tone down swearwords in subtitles, which substantiates the impression that this practice has become a convention in AVT.

Despite the absence of spatial constraints in dubbing, many swearwords are still omitted or toned down in dubbed versions of films (Adamou and Knox 2011). Soler Pardo 
(2015), for example, found that $48.8 \%$ of the swearwords in films by the director Quentin Tarantino, notorious for their abundance of swearwords, have been softened or omitted in the Spanish dubbed versions. This practice is also supported by Chaume (2004), although the argument that swearwords have a stronger impact in the written medium clearly does not apply to dubbed AVT products. In dubbing, the original soundtrack is not available to audiences, and freer translations - not just of swearwords - are therefore possible without the viewer noticing.

Tveit (2009: 89) on the other hand argues for this translation convention to be turned on its head: swearwords ought to be toned down more in dubbed than in subtitled AV products, because a written swearword "is probably only a weaker version of a word pronounced with stress and intensity". While prosodic features can clearly change the expressive meaning of swearwords (Allan and Burridge 2006; Andersson and Trudgill 1990; Jay and Janschewitz 2008), this argument is nevertheless problematic, because prosody can do both, intensify and weaken the offensiveness of swearwords.

While the convention of omitting or toning down swearwords in AVT is still practiced by the majority of the AVT industry, its validity has recently started to be questioned. Soler Pardo (2015: 204), for example, thinks it is a mistake to omit swearwords since they act as social, ethnic and cultural determinants and give us insight into a character's social class, background or culture. Han and Wang (2014: 2) note that toning down swearwords results in presenting the target language audience with an altered, inauthentic experience of a foreign culture. Hjort (2009) established through a metalinguistic questionnaire that $76.7 \%$ of her viewer respondents disagree with the statement that swearwords should be milder in subtitles (because written swearwords are stronger than spoken ones). The majority (66.2\%) prefer swearwords to be of equal strength in subtitles and dubbing. Some contractors (e.g. Netflix ${ }^{5}$ ) have recently instructed their translators to render swearwords as faithfully as possible.

The research methodology will be outlined in the next section.

\footnotetext{
${ }^{5}$ Netflix Timed Text Style Guide, Section 20. Special Instructions https://partnerhelp.netflixstudios.com/hc/enus/articles/217349997-Castilian-Latin-American-Spanish-Timed-Text-Style-Guide [accessed 08/10/18].
} 


\section{Research methodology}

The research question whether swearwords are perceived as stronger in writing/subtitles than in spoken language/dubbing was approached with a reception study. Reception studies are essential in AVT because source and target language audiences should have similar audiovisual experiences (Chiaro 2009), and AV translations should be recipient-orientated (Suojanen et al. 2015). The reception study took the form of an on-line survey in which participants rated the perceived strength of swearwords in context, i.e. in subtitled versus dubbed clips of the same AV products, by means of word scaling.

In Section 3.1, the selection criteria for the films, scenes and swearwords used in the study will be outlined and the corpus material presented. Section 3.2 describes the survey design, and Section 3.3 introduces the participants, their swearing habits and reactions to swearing.

\subsection{Corpus material}

The films which form the corpus material for the current study are American Reunion (2012), Live Free or Die Hard (2007), Forrest Gump (1994), Pulp Fiction (1994) and The Godfather (1972). These films meet three criteria: A) they contain many swearwords; B) they represent different genres; and C) they are popular in the target language culture (German). Table 1 summarises criteria B and C for the selected films, while Table 2 shows the number of swearwords in the English originals and their German subtitled and dubbed AVT versions, demonstrating criterion A.

Table 1. Corpus summary: Film title, director, year of publication; genre; number of cinema viewers in Germany

\begin{tabular}{|l|l|l|}
\hline Film title & Genre & Cinema viewers in Germany \\
\hline $\begin{array}{l}\text { Forrest Gump } \\
\text { (Zemeckis, 1994) }\end{array}$ & Drama/ romance & 7.636 .337 \\
\hline $\begin{array}{l}\text { Live Free or Die Hard } \\
\text { (= Die Hard 4.0) } \\
\text { (Wiseman, 2007) }\end{array}$ & Action & $\begin{array}{l}2.625 .423 \\
\text { (Die Hard: } 1.307 .365 \\
\text { Die Hard 2: } 1.960 .803 \\
\text { Die Hard with a Vengeance: }\end{array}$ \\
\hline
\end{tabular}

\footnotetext{
${ }^{6}$ http://www.insidekino.com
} 


\begin{tabular}{|l|l|l|}
\hline & & $\begin{array}{l}3.202 .391 \\
\text { A Good Way to Die Hard: 1.557.689) }\end{array}$ \\
\hline $\begin{array}{l}\text { American Reunion } \\
\text { (Hurwitz and } \\
\text { Schlossberg, 2012) }\end{array}$ & Comedy & $\begin{array}{l}2.521 .199 \\
\text { (American Pie: 6.168.580 } \\
\text { American Pie 2: 5.818.102 } \\
\text { American Wedding: 2.824.733) }\end{array}$ \\
\hline $\begin{array}{l}\text { The Godfather } \\
\text { (Coppola, 1972) }\end{array}$ & $\begin{array}{l}\text { Classic/ mafia \& crime/ } \\
\text { drama }\end{array}$ & 5.200 .000 \\
\hline $\begin{array}{l}\text { Pulp Fiction } \\
\text { (Tarantino, 1994) }\end{array}$ & $\begin{array}{l}\text { Neo-noir/ crime/ black } \\
\text { comedy }\end{array}$ & 1.605 .546 \\
\hline
\end{tabular}

Table 2. Number of swearwords in English original, German subtitled and dubbed AVTs

\begin{tabular}{|l|c|c|c|}
\hline $\begin{array}{c}\text { Number of swearwords } \\
\text { in the films }\end{array}$ & English & German subtitled & German dubbed \\
\hline The Godfather & 46 & 18 & 34 \\
\hline Live Free or Die Hard & 82 & 41 & 54 \\
\hline Forrest Gump & 91 & 71 & 85 \\
\hline American Reunion & 152 & 113 & 132 \\
\hline Pulp Fiction & 327 & 225 & 291 \\
\hline
\end{tabular}

Criterion A was adopted to have a sizable corpus of swearwords (total number of tokens $=43$, number of types=23), while keeping the clips, and thus the survey, short. ${ }^{7}$ Criterion B was applied because swearing is context sensitive (see Section 1). To get an overview in this exploratory survey of the topic, we wanted the corpus material to represent a wide variety of periods and genres (see Table 1); socio-physical settings; and characters of different age, cultural background/ethnicity, gender, status and occupation, in different interpersonal relationships, talking about different topics. Criterion $\mathrm{C}$ was applied because the survey participants only saw about two minutes of each film. We assumed that if the films are popular, participants are more likely to be familiar with the characters and able to put the selected clips into context. All five films meet these selection criteria.

Once the films were selected, we identified scenes suitable for use as survey clips (in line with criterion A). To be able to compare the impact of swearwords in subtitled and

\footnotetext{
${ }^{7}$ The recommended limit is 20 minutes to avoid participant fatigue and ensure a good completion rate (Revilla and Ochoa 2017).
} 
dubbed AVT products, the same TL words had to be identified in both translation modes. The aim was to compare the same words in the same contexts. Frequently, however, different TL swearwords were used for the same SL swearword in the subtitled and dubbed versions of the same scene. At other times the dubbed version of a scene included a swearword but the subtitled one did not, or (less frequently) vice versa. A methodological decision therefore had to be made: to make swearwords or context the dependent variable. As this study focuses on swearword strength, we decided to make swearwords the dependent variable and to measure the perceived strength of the same TL swearwords in different scenes. A perceived advantage of this decision is that we could compare the differential effect of one and the same TL swearword in different contexts. Our results will thus be able to contribute to the debate about the role context plays in swearword strength ratings. The URLs for the chosen clips are listed in Appendix A.

The following 11 swearwords occur in both subtitled and dubbed clips from the same films (List 1).

Table 3. Swearwords for direct comparison (subtitling vs. dubbing) (List 1)

\begin{tabular}{|l|l|}
\hline German swearwords & Approximate English equivalents \\
\hline Arsch & Arse \\
\hline Arschloch & Arsehole \\
\hline ficken & to fuck \\
\hline Mist & lit. dung, fig. crap, rubbish \\
\hline Mistkerl & lit. dung guy, fig. douchebag \\
\hline Nigger & Nigger \\
\hline Scheiße & Shit \\
\hline Schlampe & bitch/whore \\
\hline Schwein & Pig \\
\hline verdammt & damn \\
\hline Wichser & wanker \\
\hline
\end{tabular}

The following 13 swearwords (List 2) occur in either dubbed or subtitled clips and therefore cannot be directly compared.

Table 4. Swearwords in either dubbed or subtitled clips (List 2)

\begin{tabular}{|l|l|}
\hline German swearwords & Approximate English equivalents \\
\hline Nutte & Slut \\
\hline leck mich (am Arsch) & lit. lick my ass, fig. kiss my ass \\
\hline blöde Kuh & silly cow \\
\hline
\end{tabular}




\begin{tabular}{|l|l|}
\hline Makkaroniziege & lit. macaroni goat, fig. guinea \\
\hline scheißegal & fig. doesn't fucking matter \\
\hline schwul & Gay \\
\hline Tunte & faggot \\
\hline Idiot & Idiot \\
\hline Trottel & dork/moron \\
\hline dumm & stupid \\
\hline Arschgesicht & lit. ass face, fig. shitface \\
\hline Schwanz & dick/cock \\
\hline Schwanzlutscher & cocksucker \\
\hline
\end{tabular}

\subsection{Survey design}

The survey sections addressing the main research question are quantitative and use closed attitudinal scales to rate the perceived strength of the swearwords discussed in the previous section. The participants were, however, also given the opportunity to provide open-ended responses to swearword usage in the clips. These comments were analysed qualitatively through thematic analysis.

The first three survey questions elicited the participants' age, gender and mother tongue. ${ }^{8}$ Questions 4 and 5 targeted participants' swearing habits and reactions to swearing, in order to establish whether these factors play a role in the ratings. In the main part of the survey (Questions 6-48), participants rated the 43 TL (German) swearwords that could be heard in the dubbed or read in the subtitled clips on a scale from 1 (not strong at all) to 4 (very strong). Participants could, furthermore, leave optional comments on the swearwords. The summary question (Number 49) asked whether the swearwords had a stronger effect on participants in the subtitled or in the dubbed clips, or whether there was no difference. This question is similar to one in Hjort's (2009) survey and thus facilitates a direct comparison. Question 50 investigated the role genre plays in the swearword ratings. In the last question (Number 51) participants could provide additional, general feedback.

\subsection{Participants}

The survey generated a total of 110 complete responses. Of the 110 participants, $52.7 \%$ are female and $46 \%$ male; one participant does not associate with these gender categories. At $52.7 \%$ (58/110), the majority of participants are aged between 20 and 29. The next largest

\footnotetext{
${ }^{8}$ Mother tongue was included because non-native speakers have been found to show greater autonomic reactivity (Harris et al. 2003) and rate TL swearwords higher than native speakers (Jay and Janschewitz 2008: 274-275).
} 
group $(27.3 \%)$ is $30-39$ years old, while $8.2 \%$ are $50-59,6.4 \%$ are $40-49,3.64 \%$ are under 20 , and $1.82 \%$ are over 60 years old. German is the mother tongue of $93.6 \%$ of the participants and a foreign language for the remaining $6.4 \%$.

In addition to this demographic information, we also gathered information on the participants' swearing habits and reactions to swearing (Questions 4 and 5), as both can influence the perceived offensiveness of swearwords (see Section 2). This background information is presented in Table 5 and analysed in relation to the participants' swearword ratings in Section 4.

Table 5. Participants' swearing habits and reactions to swearing (Questions 4 and 5)

\begin{tabular}{|lr|lr|}
\hline \multicolumn{2}{|c|}{ How often do you swear? } & \multicolumn{2}{|c|}{ Do you feel uncomfortable when you hear someone swear? } \\
\cline { 1 - 1 } Never & $2.7 \%(3 / 110)$ & Yes, very & $2.7 \%(3 / 110)^{9}$ \\
\hline Sometimes & $56.4 \%(62 / 110)$ & \multirow{2}{*}{ Yes, somewhat } & $45.5 \%(50 / 110)$ \\
\hline Often & $36.4 \%(40 / 110)$ & & $51.8 \%(57 / 110)$ \\
\hline Very often & $4.5 \%(5 / 110)$ & No, not at all & \\
\hline
\end{tabular}

The results gathered from these participants are summarised, analysed and discussed in the next section.

\section{Results}

Swearwords are assumed to be more offensive in the written than in the spoken AVT mode (see Section 2). We question this assumption and thus seek to reject the hypothesis that swearwords are perceived as stronger in subtitles than in dubbing. The current study furthermore investigates whether other factors, such as a film's genre and participants' gender, age, native-speaker status and personal swearing habits and reactions to swearing play a significant role in swearword strength ratings. The quantitative results of the word scaling (Questions 6-50) are presented in Section 4.1. Other less quantifiable factors that may impact on the perceived offensiveness of swearwords emerged from the comments participants could leave after every swearword ranking. These were analysed qualitatively through thematic analysis. The results of this analysis are presented in Section 4.2. The final section presents a summary of the findings and discusses possible implications thereof.

\footnotetext{
${ }^{9}$ N.b. these are not the same participants who said they never themselves swear.
} 


\subsection{Quantitative analysis/results}

The first result of this reception study on swearing in AVT, included in Table 2 above, reveals that in all five films, more swearwords have been omitted in the subtitled version of the film than in the dubbed one. The TL swearwords presented in Lists 1 and 2 (Tables 3 and 4) furthermore reflect the literature on cross-cultural swearing (see Section 2). Scatological terms dominate in German, but sexual swearwords have also found their way into German target texts, possibly under the influence of English. ${ }^{10}$

The most direct answers to our research question are provided by the scores the individual swearwords achieved on the four point strength scale. Table 6 below presents the average score of every swearword included in this study. Swearwords in dubbed clips $(N=23)$ are on white background; swearwords in subtitled clips $(N=20)$ are on shaded grey background. The swearwords are arranged in order of increasing strength as rated by our participants.

Table 6. Average scores of swearwords on a scale from 1 (not strong at all) to 4 (very strong); actual ratings

\begin{tabular}{|l|l|l|}
\hline Swearword & Approximate English equivalent (fig.) & Average score \\
\hline Mist (dubbed) & crap/rubbish & 1.16 \\
\hline verdammt (subtitled) & damn & 1.23 \\
\hline Mist & crap/rubbish & 1.31 \\
\hline verdammt & damn & 1.31 \\
\hline Scheiße & shit & 1.34 \\
\hline verdammt & damn & 1.42 \\
\hline Mistkerl & douchebag & 1.45 \\
\hline blöde Kuh & silly cow & 1.46 \\
\hline verdammt & damn & 1.49 \\
\hline Scheiße & shit & 1.52 \\
\hline Mistkerl & douchebag & 1.53 \\
\hline Trottel & dork/moron & 1.55 \\
\hline Mistkerl & douchebag & 1.61 \\
\hline scheißegal & doesn't fucking matter & 1.7 \\
\hline Arsch & arse & 1.78 \\
\hline Idiot & idiot & 1.8 \\
\hline Arsch & arse & 1.81 \\
\hline
\end{tabular}

\footnotetext{
${ }^{10}$ Totals English STs: 176 scatological, 320 sexual; German TTs sub: 158 scatological, 70 sexual; German TT dub: 216 scatological, 113 sexual.
} 


\begin{tabular}{|l|l|l|}
\hline Schwein & pig & 1.85 \\
\hline Scheiße & shit & 1.9 \\
\hline Schwein & pig & 1.92 \\
\hline Arschloch & arsehole & 1.98 \\
\hline Arsch & arse & 2.01 \\
\hline Makkaroniziege & guinea & 2.01 \\
\hline Schwanz & dick/cock & 2.07 \\
\hline Arsch & arse & 2.17 \\
\hline Arschloch & arsehole & 2.17 \\
\hline Schwein & pig & 2.17 \\
\hline schwul & gay & 2.22 \\
\hline leck mich & kiss my ass & 2.28 \\
\hline Arschgesicht & shitface & 2.31 \\
\hline Tunte & faggot & 2.34 \\
\hline ficken & to fuck & 2.35 \\
\hline ficken & to fuck & 2.42 \\
\hline Wichser & wanker & 2.5 \\
\hline Schlampe & bitch/whore & 2.57 \\
\hline Nigger & nigger & 2.58 \\
\hline schwul & gay & 2.61 \\
\hline Schwanzlutscher & cocksucker & 2.65 \\
\hline Wichser & wanker & 2.65 \\
\hline Schlampe & bitch/whore & 2.84 \\
\hline Nutte & slut & 2.86 \\
\hline Schlampe & bitch/whore & 2.95 \\
\hline Nigger & nigger & 3.28 \\
\hline
\end{tabular}

The average score of all swearwords in the dubbed clips is 2.14; the average score of all swearwords in the subtitled clips is lower, at 1.898. The swearwords in the subtitled clips are thus not perceived as stronger than those in the dubbed clips.

To establish whether these results also pertain to individual participants, we calculated the average subtitling and dubbing scores for each participant. A paired t-test was run between these scores. Their respective standard deviations were 0.58 and 0.59 . This difference between the subtitling and dubbing means was found to be statistically significant, $t(109)=9.095 ; p<.001$. In percent, this means that $79.1 \%$ (87/110 participants) rated swearwords in the dubbed clips higher on average, while only $17.3 \%$ (19/110 participants) rated swearwords in the subtitled clips higher on average (actual ratings). ${ }^{11}$ The swearwords

\footnotetext{
${ }^{11}$ Four participants $(3.6 \%)$ rated every single swearword without any difference at 1 . Participants who rated the subtitled and dubbed swearwords similarly but not exactly the same might feel they rated them equally, thus responding with "no difference" to Question 49.
} 
in the subtitled clips were thus perceived as less offensive than those in the dubbed clips by the majority of participants (approx. 80\%).

The actual ratings presented in Table 6 and analysed in the previous two paragraphs make for interesting comparison with those of the perceived ratings elicited in the summary question (Number 49). In response to this question, the majority of our participants $(42.7 \%$ or 47/110) indicated that they found the swearwords in the dubbed clips more offensive; only $21.8 \%$ (24/110) felt that swearwords in the subtitled clips were stronger; 35.5\% (39/110) said there was no difference. The participants' actual ratings are thus reflected in the perceived ratings, and the results presented so far do not support the assumption/hypothesis that swearwords are perceived as stronger in subtitles than in dubbed AVTs.

Proceeding towards a more fine-grained analysis and answer to our research question, we next compared the average scores of swearwords that occur in both subtitled and dubbed clips (List 1, Table 7). These scores show little difference - the score for Mistkerl is identical; five swearwords (Mist, Schwein, Arschloch, ficken, Nigger) score marginally higher in the subtitled clips, five (scheiße, Arsch, Wichser, Schlampe, verdammt) in the dubbed clips. We therefore subjected the average scores of swearwords that occur in both subtitled and dubbed contexts (List 1) to a paired samples t-test. The results (p-values) are presented alongside the means in Table 7.

Table 7. Comparison of swearwords in subtitled and dubbed clips: means and p-values

\begin{tabular}{|l|l|l|l|}
\hline $\begin{array}{l}\text { Word (approx. fig. English } \\
\text { equivalent) }\end{array}$ & $\begin{array}{l}\text { Subtitled } \\
\text { (average) }\end{array}$ & $\begin{array}{l}\text { Dubbed } \\
\text { (average) }\end{array}$ & p-value \\
\hline Arsch (arse) & 1.79 & 2.09 & $.000^{* *}$ \\
\hline Arschloch (arsehole) & 2.17 & 1.98 & $.020^{*}$ \\
\hline ficken (to fuck) & 2.42 & 2.35 & .391 \\
\hline Mist (crap/rubbish) & 1.31 & 1.16 & $.005^{*}$ \\
\hline Mistkerl (douchebag) & 1.53 & 1.53 & .983 \\
\hline Nigger (nigger) & 3.28 & 2.58 & $.000^{* *}$ \\
\hline Scheiße (shit) & 1.34 & 1.71 & $.000^{* *}$ \\
\hline Schlampe (bitch/whore) & 2.57 & 2.895 & $.000^{* *}$ \\
\hline Schwein (pig) & 2.01 & 1.92 & .238 \\
\hline verdammt (damn) & 1.32 & 1.49 & $.001^{* *}$ \\
\hline
\end{tabular}

Four out of five of the highly significant results (**, i.e. those for Arsch, Scheiße, Schlampe, and verdammt) lead us to reject the hypothesis that swearwords are perceived as stronger in subtitling than in dubbing. Two significant results (*, i.e. those for Arschloch and Mist), and one of the highly significant results (i.e. that for Nigger), do not allow us to reject this 
hypothesis. Three comparisons are not significant (ficken, Mistkerl, Schwein). This set of results thus paint a complex picture, but more highly significant results indicate that swearwords are not necessarily perceived as stronger in subtitles than in dubbing.

To gain a better understanding of these results, we conducted individual pairwise comparisons. That is, we compared the scores of every swearword across all contexts (subtitled and dubbed) in which it occurs in our data using the Wilcoxon Signed Rank test. A summary of these results can be found in Appendix B; we discuss them in the following order: first, results that lead us to reject the hypothesis tested in this study; second, results that do not permit this conclusion; third, results that do not go in either direction; and finally, results of comparisons between individual swearword rankings in the same translation mode.

Results that allow us to reject the hypothesis that swearwords are perceived as stronger in subtitles than ins dubbing are those on Arsch 'arse', Scheiße 'shit', Schlampe 'bitch/whore' and verdammt 'damn'. Three out of four individual scores for Arsch in subtitles are highly significantly $(.000,27 \mathrm{sub}$ vs. $33 \mathrm{dub})$ or significantly $(.004,27 \mathrm{sub}$ vs. $14 \mathrm{dub})$ lower than those in dubbing. These results lead us to conclude that Arsch is not perceived as stronger in subtitles than in dubbing. The individual comparisons for Scheiße in subtitled and dubbed clips ( $15 \mathrm{sub}$ vs. $12 \mathrm{dub}$ at $.003^{*}$, and $15 \mathrm{sub}$ vs. $20 \mathrm{dub}$ at $.000^{* *}$ ) show that this swearword is not perceived as stronger in subtitles than in dubbing either. The individual comparisons for ratings of Schlampe in the subtitled clip (47sub) are highly significantly (.000** in $47 \mathrm{sub}$ vs. $35 \mathrm{dub})$ or significantly (.001* in $47 \mathrm{sub}$ vs. $19 \mathrm{dub})$ lower than in the dubbed clips. All results on Schlampe thus indicate that this swearword is not perceived as stronger in the written than in the spoken AVT mode too. Two of the individual comparisons for verdammt are statistically highly significant (.000** in 16 sub vs. 36dub) or significant (.004* in 28 sub vs. 36dub); one is not significant (40sub vs. 36dub at .206). The results on verdammt also lead us the reject the assumption/hypothesis we are testing. All results discussed so far thus indicate that swearwords are not perceived as stronger in subtitling than in dubbing.

Three individual comparisons do not allow us to reject our hypothesis. The written forms of the swearwords Arschloch 'arsehole' (in 29sub), Mist 'crap/rubbish' (in 30sub), and Nigger (in 9sub) in subtitled clips are all ranked higher than their spoken/dubbed counterparts (in 17dub, 24dub and 43dub); two of the differences are significant (Arschloch in 29sub vs. $17 \mathrm{dub}$ at $.020^{*}$ and Mist in $30 \mathrm{sub}$ vs. $24 \mathrm{dub}$ at $.005^{*}$ ), and one is highly significant (Nigger in 9sub vs. 43dub at .000). These comparisons do not allow us to reject the hypothesis that swearwords are perceived as stronger in subtilling than in dubbing and instead support the literature on the topic to date. 
The results of the individual comparisons between Mistkerl 'douchebag', Schwein 'pig' and Wichser 'wanker' are not significant and therefore support the "no difference" answers to the perceived ratings (Question 49).

This leads us to the individual comparisons between the same swearwords in the same translation mode. We conducted this comparison because - in a study based on naturally occurring data (and not controlled experiments; see Section 3.1) - this is the only way we can quantitatively test the effect of context on swearword strength perception. The results indicate that context is important, but in $60 \%$ of cases the swearword itself seems to be more important than the context. More specifically, for 6/10 swearwords that occur more than once in the same translation mode but in different clips, the mean rankings of the swearwords in both contexts are not significantly different (Arsch 41 sub vs. $27 \mathrm{sub}$ p=.582, Arsch 33dub vs. 14dub $\mathrm{p}=.05$, Mistkerl 6sub vs. $42 \mathrm{sub} \mathrm{p}=.095$, Schlampe $19 \mathrm{dub}$ vs. $35 \mathrm{dub} \mathrm{p}=.088$, and verdammt 16 sub vs. 28 sub p=.168). In $40 \%$ of cases, the same swearword in the same translation mode but in different scenes/contexts, leads to significantly different strength ratings (Scheiße 12 dub vs. 20dub, schwul 13 dub vs. $23 \mathrm{dub}$, verdammt 16 sub vs. 40 sub $\mathrm{p}=.000$ and Schwein 7 sub vs. 39sub $\mathrm{p}=.004)$. These results support the methodological decision to make swearwords the dependent variable (because in $60 \%$ of the cases the swearword itself is more important than the context). They furthermore demonstrate the importance of context for the perceived offensiveness of swearwords and thus warrant the (quantitative and qualitative) investigation of contextual variables in this study.

To summarise the results to our main research question, all of them suggest that swearwords are not perceived as stronger in the written translation mode, i.e. subtitling, than in the spoken mode, i.e. dubbing. The strength ratings, both overall and by individual participants, as well as the comparison between the actual (Questions 6-50) and perceived (Question 49) rankings paint a clear picture; the more fine-grained comparisons between swearwords that occur in both AVT modes in our corpus show that other factors such as context can significantly influence participants' ratings. The results for the quantifiable variables selected for examination in this study (gender, age, native-speaker status, personal swearing habits, reaction to swearing and genre) are presented and analysed next.

To establish whether there is a relationship between swearword ratings in subtitled and dubbed AVTs and demographic variables (gender and age), a regression analysis was conducted. A two-way mixed ANOVA was run to determine whether the AVT type or the participants' gender impacted the average scores. A statistically significant main effect for gender was found $(\mathrm{F}(1.107)=5.32, \mathrm{p}=.023)$ with the female participants rating swearwords 
higher on average than the male participants. A Pearson's correlation test was run between the participants' age and their ratings. No correlation was found. Our group of non-native speakers of German was too small to run statistical significance tests on the ratings of native vs. non-native speakers.

To examine the effect of the participants' swearing habits (Question 4) and reaction to swearing (Question 5) on ratings, two independent t-tests were run between participants' average scores and their responses to these two questions. The average ratings of participants who swear never or sometimes (Group 1, see Table 5, Section 3.3) are higher ( $\mathrm{n}=65, \mathrm{M}=2.18$, $\mathrm{SD}=0.59$ ) than the average ratings of participants who swear often or very often (Group 2) $(\mathrm{n}=45, \mathrm{M}=1.78, \mathrm{SD}=0.45)$. This difference was found to be statistically significant, $t(108)=3.798, p<.001$. Likewise, the average ratings of participants who report strong negative reactions to swearing (Group 1) are higher $(\mathrm{n}=53, \mathrm{M}=2.25, \mathrm{SD}=0.55)$ than the average ratings of participants who do not feel (very or somewhat) uncomfortable in the vicinity of swearing (Group 2) $(\mathrm{n}=57, \mathrm{M}=1.80, \mathrm{SD}=0.50)$. This difference was also found to be statistically significant, $\mathrm{t}(108)=4.468, \mathrm{p}<.001$. These results confirm that the demographic variables gender and age, as well as people's swearing habits and reactions to swearing significantly impact the perceived offensiveness of swearwords.

Swearing has furthermore been shown to be genre-specific (see Section 2). We selected films of different genres as corpus material for this study (cf. Section 3.1) to be able to examine whether genre impacts on swearword strength ratings. The majority of our participants $(63.6 \% ; 70 / 110)$ believe genre is an important influence on how strongly swearwords are perceived. This result is also reflected in the average scores of the films, as shown in Figure 1. 
Figure 1: Average scores of genre by film

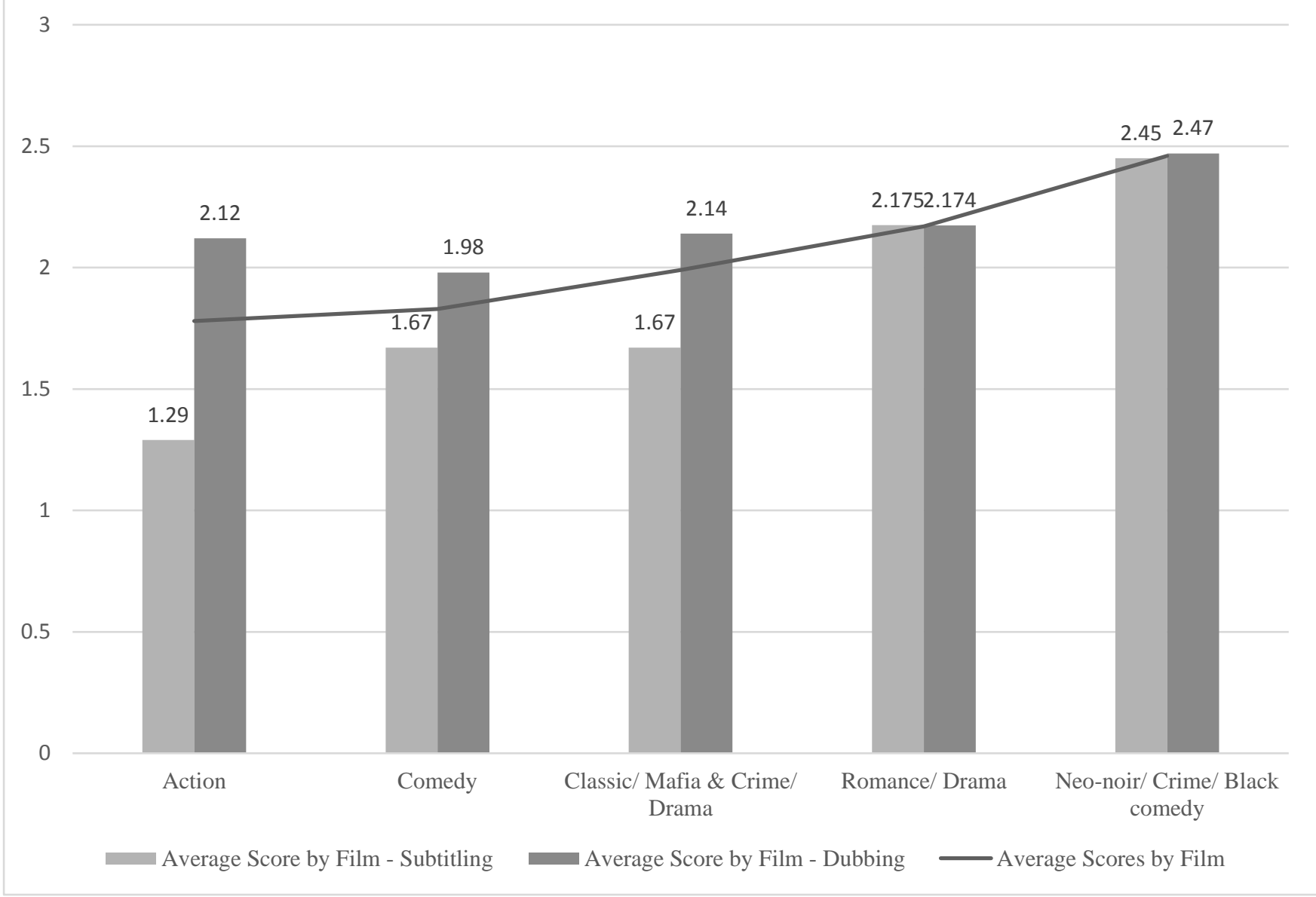

The results presented in Figure 1 show that swearwords are perceived as least offensive in the film that represents action in our filmography (Die Hard). Average strength ratings then gradually increase from comedy (American Reunion) to mafia (The Godfather) to romance / drama (Forest Gump) to peak at the film that represents noir / crime / black comedy, i.e. Pulp Fiction. The differences between the light and dark grey bars in Figure 1 furthermore graphically illustrate the main finding of this study, i.e. that swearwords are perceived as stronger in the dubbed version of these films than in the subtitled ones.

In order to obtain a deeper understanding of participants' motivations behind their ratings, we provided them with the opportunity to leave comments under the rating scales (648), the question on genre (50) and on the survey in general (51). 78/110 participants utilized this opportunity and left a total of 610 comments. Each question generated comments, with spikes at certain words. 


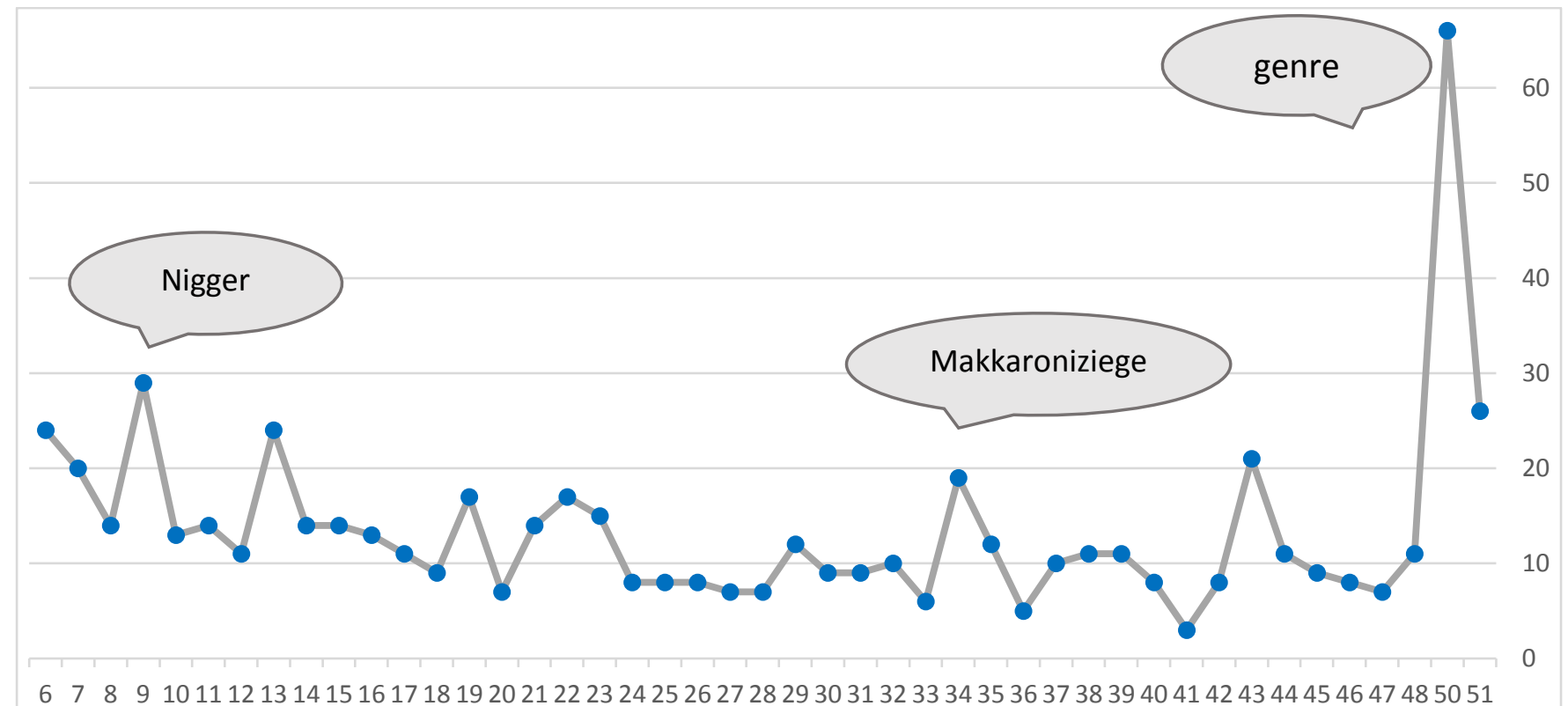

Figure 2. Number of comments per swearword

With 66/610, the question on the role a film's genre plays in the perception of swearing (Question 50) generated the most comments. Nigger in Forrest Gump (Question 9), the highest rated word in this survey (see Table 6), generated the largest number of comments (29/610) among the individual swearwords (Questions 6-48). To establish whether the quantity of comments a question triggered correlates with higher ratings, a Pearson's correlation test was run. The test showed a moderate positive relationship between the number of comments made at each question and the average ratings at each question. This correlation was found to be statistically significant, $r=.444, p=.003$. We can thus conclude that the higher a swearword's strength rating, the more participants had to say about it.

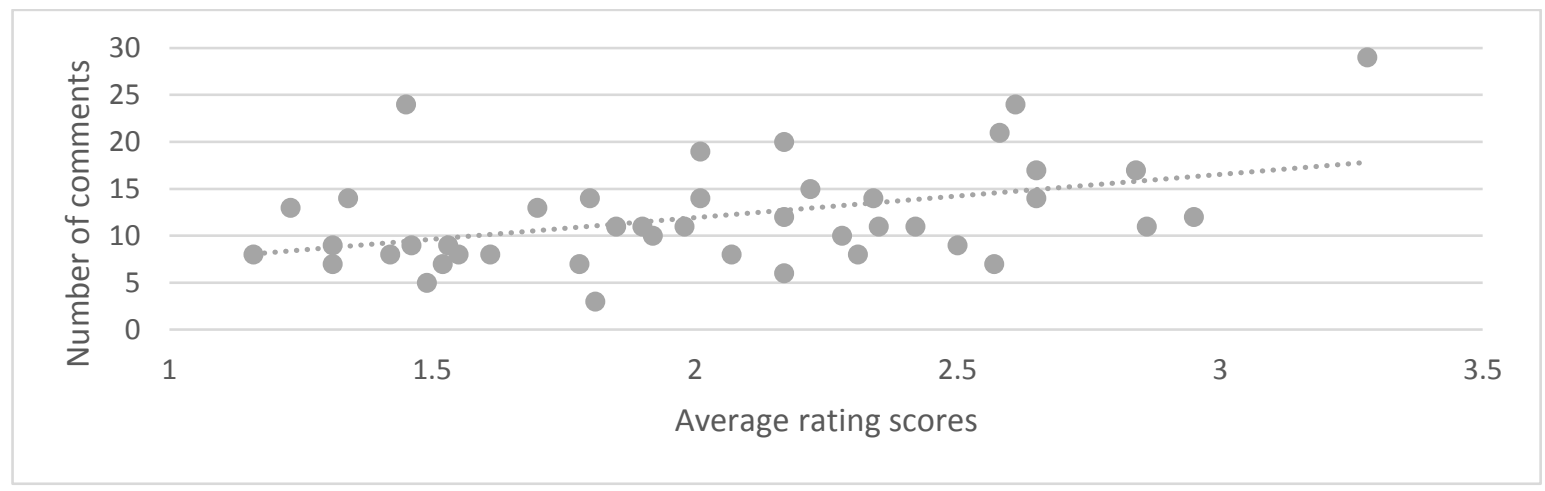

Figure 3. Correlation number of comments and average strength rating scores

More generally, the high uptake of the comment options can be considered a good indicator of the relevance of the topic under investigation in this study. In the next section we present the qualitative analysis of the open-ended responses. 


\subsection{Qualitative results}

Factors that do not lend themselves to quantitative analysis were explored through thematic analysis of respondents' comments. Thematic analysis, a method for exploring data sets and identifying patterns within them, is particularly useful for examining the perspectives of different research participants and the investigation of new data sets or topics we know little about (Braun and Clarke 2006). The data were independently coded by both authors; the number of coding references given in brackets below can thus be higher than the number of comments. The coders achieved agreement levels of $80.4-100 \%$ on individual questions (with a mean of $95.58 \%)$.

Analysis of the comments revealed that swearing is a topic our participants know a lot about. The defining characteristics and functions of swearing reviewed in Section 2 also emanated from the inductive coding of our data. The new results identified through the analysis largely pertain to the differential effect of swearing in subtitling and dubbing. The results of the qualitative analysis are discussed according the five themes (patterns) that were determined by the coding of the comments. The first theme captures the characteristic of swearing and includes the main addressees of swearwords in our corpus; the second theme focuses on (negative, positive or neutral) functions of swearwords; the third theme identifies the main determinants of swearword strength. The next themes are more specific to swearing in $\mathrm{AV}(\mathrm{T})$ : theme four explores the use of swearwords as a stylistic device in film(script)s; theme five focuses on translation, and theme six centres round viewer/participant characteristics.

221 coding references grouped under the first theme relate to low swearword strength ratings because defining characteristics of swearwords are violated in the clips. The large number of coding references under this theme show how well our participants know what swearing is (and is not). If an expression represents everyday language use $(60)^{12}$, or is said in a tone of voice/with a prosodic contour that indicates inoffensiveness (34), it does not qualify as a swearword (38). Words barely count as swearwords when they are antiquated (34), or used in a genuine (24) or literal (11) way. Our participants, moreover, differentiate between swearwords being used as address terms (7), slang (15) and slurs (21), i.e. derogatory or

\footnotetext{
${ }^{12}$ The figures in brackets refer to the number of coding references at a specific thematic node or sub-node.
} 
insulting terms applied to particular groups of people. As for the latter, they mainly target ethnic groups ("racist", 38), or are homophobic (30) or sexist (26).

The results on whether swearwords have a negative, neutral or positive function (theme two) are in line with the literature. Swearing is predominantly perceived as negative (257); this effect is largely created by its pejorative nature (94). Swearwords are regarded as particularly negative when they are used aggressively and target personal weaknesses (12). Swearword use can also be considered neutral or appropriate (148), especially if the swearword is used en passant (116), or if it is "warranted" (19). Swearwords have a positive function when they create humour (58), release emotional energy (27) or act as a compliment or sign of respect (15).

The main determinants of swearword strength (theme three) that emerged from the thematic analysis are contextual factors (373) and addresser/addressee characteristics, i.e. attributes of characters participating in swearing in the clips and their relationship (159). Table 8 summarises the coding for this key theme.

Table 8. Determinants of swearword strength (number of coding references)

\begin{tabular}{|l|l|}
\hline Swearword strength depends on... & $\mathbf{6 5 4}$ \\
\hline addressee_body_insitution (e.g. army, mafia) & 54 \\
\hline addresser_addressee_demographic_characteristics & 49 \\
\hline addresser_addressee_status and social distance & 43 \\
\hline addressee_inanimate & 13 \\
\hline context_general & 114 \\
\hline context_film_genre_director_scene & 145 \\
\hline context_linguistic & 84 \\
\hline context_era_time & 31 \\
\hline
\end{tabular}

Starting with addresser/addressee characteristics, our participants expect swearwords in certain socio-physical/instituional settings (54, e.g. army, underworld) and perceive them as mild when used by members of such bodies. Demographic characteristics (age, sex, ethnicity) of the users/recipients of swearwords were identified as the second most important addresser/addressee-related determinant of swearword strength (49). This category is followed by the perceived social status (superior vs. subordinate) or distance (high vs. low solidarity) of the addresser/addressee (43). Swearwords directed towards inanimate objects 
are generally perceived as weak (13). The most frequently quoted specific contextual determinant of swearword strength was the film's genre, director or specific scene in which the swearword occurs (145). Eighteen participants note that swearwords "belong" in films of some genres; they would be "unrealistic" without swearwords. The linguistic context of the swearword is the second most important contextual determinant of swearword strength (84). Linguistic context encompasses the frequency with which a swearword is uttered (once or repeatedly); whether it is said straight to the addressee's face or used indirectly; and the formality of language used in the scene, including the presence of other swearwords. The era a film is set in (or the time in which it was made) constitute the third most frequently given explanation for a specific rating in this category (31).

The next three themes to emerge from the analysis are more specific to (the AVT of) films. Our participants are aware that swearwords can function as a stylistic device (theme four, 131 coding references), mainly for depicting characters as good or bad (51), unintelligent and/or immature (24), or vulgar and/or low-class (4). Frequently, swearwords simply form part of an idiolect, i.e. a character's idiosyncratic way of speaking (39). According to our participants, protagonists in some movies or genres "have to" swear; a lack of swearing by certain characters in specific genres (e.g. gangster) would result in a loss of authenticity.

Theme five relates directly to the audiovisual translation of swearwords. Theme five is the second largest theme (438) established by the qualitative analysis (after theme three "Swearword strength depends on ...." with 654 coding references, see Table 8), despite the survey not explicitly mentioning AVT. Most comments coded under theme five relate to (translation) reasons for why a swearword had a diminished (84) or heightened (61) effect in a particular context. Four times more comments note that a specific swearword was perceived as stronger in the English original (80) than in the German translation (18). This result directly relates to the 45 mentions of swearwords being toned down in translation. Our participants furthermore explicitly remark on the quality of the translation (58 positively, 40 negatively, with 26 participants considering the German translation to be inappropriate or even wrong), and the way the translation is perceived in the two translation modes. Subtitling (25) was mentioned twice as often as dubbing (12), but participants also commented on the German translation in the dubbed clips, speculating about the English original (9). Several participants noted that they struggled with the evaluation of the swearwords in the subtitles because they heard the original on the audio track, understood it and compared it with the one in the subtitles (64). 
"The rating was difficult because I understand English and the English expression seemed stronger to me than the one in the German subtitle." (Participant 14144165) ${ }^{13}$

"I believe that the effect of the swearwords in the subtitled clips was diminished because you could hear the original and - if you understand English - hear that the swearwords were partly stronger there." (Participant 14175565)

The flip side of the coin, i.e. participants not being able to compare swearword strength in dubbing, was also commented on.

"I rated swearwords in subtitles differently because I could hear (and understand) the original and noticed the discrepancy between e.g. motherfucker and Mistkerl. In the dubbed version you don't know what was said in the original and are less biased." (Participant 14094096)

Directly pertaining to our research question, only one participant comment supports the assumption that swearwords are perceived as stronger in subtitles than in dubbing (Arsch 'arse' seemed “a little stronger in writing than in speech", Participant 14299314). Six coded comments explicitly state the opposite (e.g. "in the subtitles expletives are much less aggressive than when spoken", Participant 4142743; "swearwords ... have a weaker effect in the purely written medium", Participant 14144165). Two of these comments are cross-coded with prosody in theme one and thus support Tveit's view that a swearword can sound stronger when spoken aloud with intensity and force than when read silently.

The sixth and last theme established through the qualitative analysis of the comments centres around viewer/participant characteristics. The methodological choice to include questions on personal swearword use and reactions to swearing was vindicated by 179 references pertaining to these issues (e.g. "I use Mistkerl myself, don't really consider it as a swearword", Participant 14214897; "Possibly I'm influenced by my feminist views...", Participant 14363952). Explicit references to personal expectation were also coded 21 times, but mainly in connection with other contextual factors. Fourteen references refer to swearwords going unnoticed in the clips, either because they were so weak (e.g. "I almost missed this because I heard it more as an "Oh no!" [rather than as a swearword]", Participant

\footnotetext{
${ }^{13}$ All direct quotes from the comments are our translations from German.
} 
14097637), or because the participant focused on other aspects of the clip.

How the findings of the thematic analysis match up with those of the quantitative analysis and previous research will be discussed in the next section.

\subsection{Discussion}

The research question we address in this paper is whether swearwords are perceived as stronger in subtitling, the written AVT mode, than in dubbing, the auditory mode. The central result we are thus looking for is a difference in participant ratings between swearwords in the subtitled and dubbed clips. The average scores of each swearword on a scale of 1 (not strong at all) to 4 (very strong) in the actual ratings (Questions 6-48, Table 6) and the total average of subtitling and dubbing scores (1.9 vs. 2.14) reveal that swearwords in the subtitled clips were rated lower on average than those in the dubbed clips. The subtitled swearwords were therefore not perceived as stronger than the dubbed ones. On the contrary, our participants rated the swearwords in subtitles significantly lower on average $(\mathrm{p}<.001)$ than those in dubbing. This result also holds for the participants' individual actual ratings and the perceived ratings, i.e. the responses to Question 49. In this question the majority of participants (43\%) indicated that the swearwords in the dubbed clips are stronger than those in the subtitled clips, $36 \%$ found no difference, and only $22 \%$ stated that they perceived the swearwords in the subtitled clips as more offensive than those in the dubbed clips.

These results are remarkably similar to Hjort's (2009). 23.3\% of Hjort's 133 respondents do not want swearwords to be milder in subtitles; the majority (66.2\%) prefer swearwords to be equal in strength despite the different translation modes. Like Hjort's, several of our participants expressed annoyance about milder renderings of swearwords. Hjort (2009) and Adamou and Knox (2011) attribute this to a violation of the norm that subtitles ought to be as inconspicuous as possible. Our results point in a similar direction. Directly, in that our participants commented on the difficulty of rating swearwords in subtitles because they understood the English originals on the audio track (see section 4.2); indirectly, in that 64 coding references relate to our participants having compared the SL and TL swearword, indicating that their attention was drawn to how the swearword was rendered in translation, suggesting that the AVT was not inconspicuous.

The more fine-grained quantitative analysis, the comparison of the means of swearwords that occur in both subtitled and dubbed clips and the individual pairwise comparisons, revealed that other factors clearly also play a role in swearword perception. The 
thematic analysis helped identify these. By far the most important factor influencing perceived swearword strength, as identified by our participants, is context. This includes the genre and/or director of the film (including the time in which it was made or set), the socialphysical setting (including public vs. private, formal vs. informal), the linguistic context and speech act (direct vs. indirect) in which the swearwords are used, as well as sociodemographic and personal characteristics of both the on-screen characters and the viewers/participants (cf. Gambier 2018: 57).

The swearword Schwein 'pig' illustrates this point well. Our corpus material contains three tokens of Schwein, two subtitled (7 and 39sub) and one dubbed (37dub). We saw in Section 4.1. that the difference in strength ratings between occurrences in the subtitled and dubbed clips is not significant (Table 7), but the difference in the same translation mode is. The comments reveal that this is due to the different contexts in which the swearword occurs. In the subtitled clip from Forrest Gump (7sub), the character Earl insults black people by calling them 'black pigs' (see Footnote 3 for multiword swearing expression). The average rating of Schwein in this context was 2.17. Ten participants commented that this use of Schwein is highly offensive and racist; one (Participant 14111419) specifically noted that it is the context that makes the offence so serious here. In the dubbed clip from The Godfather, Connie Corleone calls her cheating and abusive husband 'you pig, you dirty pig' (37dub). The average rating of Schwein in this context is 1.91. Six participants empathized with Connie and found her use of this swearing expression "reasonable" or "appropriate" in this context. Participant 14100424, for example, thinks that Connie's husband has "deserved" this epithet. The context for the third instance of Schwein, from the subtitled version of The Godfather, is Connie telling her brother about the row with her husband, who then calls his brother-in-law a 'mean pig' (39sub). This instance was rated 1.85 on average. Here participants seemed more concerned with the toned-down translation of son of a bitch as Schwein than with the swearword itself (7/11 comments). This example illustrates that one and the same swearword gets rated differently in different contexts (Jay and Janschewitz 2008), or as Participant 14096009 put it: "Schwein ist nicht gleich Schwein" 'It's not like for like, there are pigs and there are pigs'.

The pragmatic/contextual variables found to influence perceived swearword strength in previous research (see Section 2; e.g. Allan and Burridge 2006; Fernández Fernández 2009; Filmer 2012; Jay and Janschewitz 2008) thus also operate in our study. Our more specific quantitative results, as well as the qualitative analysis, support findings which have shown 
that the strength of swearwords is context-sensitive, i.e. what is dysphemic in one context does not have to be in another.

Other previously identified factors (Allan and Burridge 2006; Holmes 2013; Jay 2017; Ljung 2011; McEnery 2006; Mehl and Pennebaker 2003), such as gender, personal swearing habits and reactions to swearing, are also reflected in our participants' swearword ratings. Although men and women swear at roughly the same rate nowadays (Jay and Janschewitz 2008: 272; McEnery 2006), we found clear gender differences in our participants' ratings: women rated significantly higher on average than men, but both male and female participants rated swearwords in the subtitled clips lower than those in the dubbed clips. This result is therefore in line with the literature on gender differences in swearing (see Section 2). Regardless of gender, participants who do not often swear themselves, and who feel uncomfortable when they hear someone else swear (Group 1, see Section 4.1), rated higher on average than participants who swear relatively frequently themselves and do not mind overhearing someone else swear (Group 2). In contrast with McEnery's (2006) corpus study on the use of swearwords in English (see Section 2), we found no correlation between participants' age and their ratings. Our group of non-native speakers of German was too small to run statistical significance tests on the ratings of native vs. non-native speakers. This is a line of research we would like to pursue in future.

The main results of this reception study of swearing in AVT clearly indicate that participants do not feel that the investigated swearwords are stronger in writing and should thus be toned down in subtitles. In the discussion, we therefore focused on and illustrated contextual variables which influence swearword perception. Expressed in terms of the classic Lasswell (1948) formula, "Who says what in which channel to whom with what effect?", it is not just the 'what' (the swearing expression), and the AVT 'channel' (subtitling or dubbing) which determine the impact of a swearword on the audience, but also the 'who' and 'to whom' (the participating characters and their relationship), the setting and the linguistic context, as well as the genre/director of the film and the personal characteristics of its viewers.

\section{Conclusion}

In this reception study we empirically tested the assumption that swearwords are perceived as stronger in subtitles than in dubbed AVTs. The results of several types of quantitative and qualitative analyses indicate that our participants do not find swearing more offensive in 
subtitles than in dubbed audiovisual products. Factors such as the genre of the film, the participants' gender, personal swearing habits and reactions to swearing all played a role in the ratings, but interactions between these variables were not found. This means that swearing expressions in the subtitled clips were always rated lower on average than the words in the dubbed clips, regardless, for example, of the genre of the film. The results of this reception study thus do not support the assumption that swearwords are perceived as stronger in subtitling than in dubbing. Some translators (see Hjort 2009: 4), researchers (e.g. Hjort 2009; Soler Pardo 2015; Tveit 2009) and contractors (e.g. Netflix) have started to question or revoke this assumption. We have provided empirical evidence that this assumption seems to be unjustified and that the long-held AVT convention to tone down or omit offensive language more in subtitles than in dubbing should be removed from AVT textbooks and guidelines for subtitles altogether.

Following on from this exploratory project and the results it generated, we intend to investigate the more general claim that swearing is more offensive in writing than in spoken language. Our results indicate that this claim may also be too general, but subtitling is of course not writing. In future research we would furthermore want to adopt a more controlled experimental design by re-subtitling clips so that participants rate the same swearwords in the same contexts. Other variables that could be controlled are, for example, viewers' knowledge of the source language and the source language itself. For the current study, many participants being able to understand the SL in the subtitled clips was considered an advantage, because they could make informed judgments. Future research using a SL that is not as widely understood as English could yield different results. Detailed analyses of translation practices for swearing in subtitling and dubbing, similar to Fernández Dobao's (2006) study on English into Spanish or Han and Wang's (2014) study on English into Chinese, would furthermore provide an important foundation for future reception studies on swearing.

Research on the topic of swearing in AVT has just begun. We have provided first empirical evidence to challenge the assumption that swearing expressions are perceived as stronger in subtitles than in dubbed audiovisual products. This finding can and should impact on AVT training and practice so that target audiences receive a similar quality product as source language audiences: swearwords that are not omitted or toned down but rendered faithfully by an equally strong target language expression. 


\section{Bibliography}

Adamou, Christina \& Simone Knox. 2011. Transforming television drama through dubbing and subtitling: Sex and the Cities. Critical Studies in Television 6(1). 1-21.

Allan, Keith \& Kathryn Burridge. 2006. Forbidden words: Taboo and the censoring of language. Cambridge: Cambridge University Press.

Andersson, Lars-Gunnar \& Peter Trudgill. 1990. Bad Language. Oxford \& Cambridge, Mass.: Basil Blackwell.

Beers Fägersten, Kristy. 2012. Who's swearing now? The social functions of conversational swearing. Newcastle-upon-Tyne: Cambridge Scholars Publishing.

Beers Fägersten, Kristy \& Karyn Stapleton (eds.). 2017. Advances in swearing research. New languages and new contexts. Amsterdam: John Benjamins.

Braun, Virginia \& Victoria Clarke. 2006. Using thematic analysis in psychology. Qualitative Research in Psychology 3(2). 77-101.

Carstensen, Kathrine. 2012. Wie werden Kraftausdrücke übersetzt? Ein Vergleich zwischen Untertitel und Synchronisation am Beispiel von Das Fest. Aarhus Universitet.

Chaume, Frederic. 2004. Cine y traducción. Madrid: Catedra.

Chiaro, Delia. 2009. Issues in audiovisual translation. In Jeremy Munday (ed.), The Routledge companion to translation studies, 141-165. London: Routledge.

Díaz Cintas, Jorge \& Aline Remael. 2007. Audiovisual translation: Subtitling. Manchester \& Kinderhook, NY: St. Jerome Pub.

Díaz Cintas, Jorge \& Gunilla M. Anderman (eds.). 2009. Audiovisual translation: Language transfer on screen. Basingstoke: Palgrave Macmillan.

Díaz Cintas, Jorge \& Josélia Neves (eds.). 2015. Audiovisual translation: Taking stock. Newcastle upon Tyne: Cambridge Scholars Publishing.

Fernández Dobao, Ana M. 2006. Linguistic and cultural aspects of the translation of swearing: The Spanish version Of Pulp Fiction. Babel 52(3). 222-242.

Fernández Fernández, María J. 2009. The translation of swearing in the dubbing of the film South Park into Spanish. In Jorge Díaz Cintas (ed.), New trends in audiovisual translation, 210-225. Bristol: Multilingual Matters.

Filmer, Denise A. 2012. The 'gook' goes 'gay' - Cultural interference in translating offensive language. Intralinea 14. http://www.intralinea.org/archive/article/1829 (accessed 23 February 2017).

Gambier, Yves. 2018. Translation studies, audiovisual translation and reception. In Elena Di Giovanni \& Yves Gabmier (eds.), Reception studies and audiovisual translation, 43-66.

Amsterdam: John Benjamins. 
Gauger, Hans-Martin. 2012. Das Feuchte und das Schmutzige. München: C. H. Beck.

Gottlieb, Henrik. 1994. Subtitling: Diagonal translation. Perspectives: Studies in Translatology 2(1). 101-121.

Han, Chong \& Kenny Wang. 2014. Subtitling swearwords in reality TV series from English into Chinese: A corpus-based study of The Family. The International Journal for Translation \& Interpreting Research 6(2). 1-17.

Harris, Catherine L., Ayse Ayçíçeğí \& Jean Berko Gleason. 2003. Taboo words and reprimands elicit greater autonomic reactivity in a first language than in a second language. Applied Psycholinguistics 24(4). 561-579.

Hjort, Minna. 2009. Swearwords in subtitles. inTRAlinea. Special Issue: The translation of dialects in multimedia. http://www.intralinea.org/specials/article/1718 (accessed 5 February 2017).

Holmes, Janet. 2013. An introduction to sociolinguistics, 4th edn. London: Routledge.

Ivarsson, Jan \& Mary Carroll. 1998. Subtitling. Simrishamn: TransEdit.

Janschewitz, Kristin. 2008. Taboo, emotionally valenced, and emotionally neutral word norms. Behavior Research Methods 40(4). 1065-1074.

Jay, Timothy. 1977. Doing research with dirty words. Maledicta: The International Journal of Verbal Aggression 1. 234-256.

Jay, Timothy. 1992. Cursing in America. Philadelphia: John Benjamins.

Jay, Timothy. 2000. Why we curse. Philadelphia: John Benjamins.

Jay, Timothy. 2009. The utility and ubiquity of taboo words. Perspectives on Psychological Science 4(2). 153-161.

Jay, Timothy, Catherine L. Caldwell-Harris \& Krista King. 2008. Recalling taboo and nontaboo words. American Journal of Psychology 121. 83-103.

Jay, Timothy \& Kristin Janschewitz. 2008. The pragmatics of swearing. Journal of Politeness Research 4(2). 267-288.

Lasswell, Harold D. 1948. The structure and function of communication in society. In Lyman Bryson (ed.), The communication of ideas, 37-51. New York: Harper and Row.

Ljung, Magnus. 2009. The functions of expletive interjections in spoken English. In Antoinette Renouf \& Andrew Kehoe (eds.), Corpus linguistics: Refinements and reassessments (Language and Computers: Studies in Practical Linguistics 6), 155-171. Amsterdam: Rodopi.

Ljung, Magnus. 2011. Swearing: A cross-cultural linguistic study. London: Palgrave Macmillan UK. 
McEnery, Anthony. 2006. Swearing in English: Bad language, purity and power from 1586 to the present. London: Routledge.

McEnery, Anthony \& Zhonghua Xiao. 2004. Swearing in modern British English: the case of fuck in the BNC. Language and Literature 13(3). 235-268.

Mehl, Matthias \& James W. Pennebaker. 2003. The sounds of social life: A psychometric analysis of students' daily social environments and natural conversations. Journal of Personality and Social Psychology 84. 857-870.

Montagu, Ashley. 2001. The anatomy of swearing. Philadelphia: University of Pennsylvania Press.

Nübling, Damaris \& Marianne Vogel. 2004. Fluchen und schimpfen kontrastiv. Germanistische Mitteilungen 59. 19-33.

Ofcom. 2016. Attitudes to potentially offensive language and gestures on TV and radio. London: Ipsos Mori. Available at: https://www.ofcom.org.uk/_data/assets/pdf_file/0022/91624/OfcomOffensiveLanguage.pdf (Accessed: 5 May 2019).

Pinker, Steven. 2006. The blank slate. General Psychologist 41(1). 1-8.

Pinker, Steven. 2007. Dating, swearing, sex and language: A conversation with questions between Steven Pinker and Ian McEwan. Areté: The Arts Tri-Quarterly 24. 81-100.

Revilla, Melanie \& Carlos Ochoa. 2017. Ideal and maximum length for a web survey. International Journal of Market Research 59(5). 557-565. https://doi.org/10.2501/IJMR2017-039 (accessed 10 May 2018).

Roffe, Ian. 1995. Teaching, learning and assessment strategies for interlingual subtitling. Journal of Multilingual and Multicultural Development 16(3). 215-225.

Sánchez, Diana. 2004. Subtitling methods and team-translation. In Pilar Orero (ed.), Topics in Audiovisual Translation, 9-17. Amsterdam: John Benjamins.

Soler Pardo, Betlem. 2015. On the translation of swearing into Spanish: Quentin Tarantino from Reservoir Dogs to Inglorious Basterds. Newcastle Upon Tyne: Cambridge Scholars Publishing.

Suojanen, Tytti, Kaisa Koskinen \& Tiina Tuominen. 2015. User-centered translation (Translation practices explained). London: Routledge.

Tveit, Jan-Emil. 2009. Dubbing vs. subtitling: Old battleground revisited. In Jorge Díaz Cintas \& Gunilla M. Anderman (eds.), Audiovisual translation: Language transfer on screen, 85-96. Basingstoke: Palgrave Macmillan.

Van Lancker, Diana \& Jeffrey Cummings. 1999. Expletives: Neurolinguistic and neurobehavioral perspectives on swearing. Brain Research Reviews 31(1). 83-104. 


\section{Filmography}

American Reunion. 2012. Jon Hurwitz \& Hayden Schlossberg. USA, 108 minutes. Forrest Gump. 1994. Robert Zemeckis. USA, 136 minutes.

Live Free Or Die Hard. 2007. Len Wiseman. USA, 123 minutes.

Pulp Fiction. 1994. Quentin Tarantino. USA, 148 minutes.

The Godfather. 1972. Francis Ford Coppola. USA, 170 minutes.

\section{Appendix A}

The clips from these films used in this survey are available on Google Drive https://drive.google.com/drive/folders/1Y7CWfxEvjG3WBpV8idSbIHd-kPgpZgJ_ 


\section{Appendix B}

Individual pairwise comparisons of all swearwords in both AVT modes

\begin{tabular}{|c|c|c|c|c|c|c|c|}
\hline SW & Qu no + sub vs. dub & $\begin{array}{l}\text { mean } \\
\text { sub }\end{array}$ & $\begin{array}{l}\text { mean } \\
\text { dub }\end{array}$ & $\begin{array}{l}\mathrm{Z} \\
\text { scores }\end{array}$ & $\begin{array}{l}\mathrm{p} \\
\text { values }\end{array}$ & Bonferoni & $\begin{array}{l}\text { Sig @ } \\
0.05\end{array}$ \\
\hline \multirow[t]{7}{*}{ Arsch } & 41sub vs. $27 \mathrm{sub}$ & 1.81 & 1.78 & -.551 & .582 & .0083 & NS \\
\hline & 27 sub vs. 14 dub & 1.78 & 2.01 & -2.902 & .004 & .0083 & $*$ \\
\hline & 27sub vs. 33dub & 1.78 & 2.17 & -4.625 & .000 & .0083 & $* *$ \\
\hline & 41 sub vs. 14 dub & 1.81 & 2.01 & -2.111 & .035 & .0083 & NS \\
\hline & 41sub vs. 33dub & 1.81 & 2.17 & -4.449 & .000 & .0083 & $* *$ \\
\hline & 33dub vs.14 dub & 2.17 & 2.01 & -1.960 & .050 & .0083 & NS \\
\hline & $\begin{array}{l}27+41 \text { sub avg vs. } \\
14+33 \text { dub avg }\end{array}$ & 1.79 & 2.09 & -4.511 & .000 & $\mathrm{n} / \mathrm{a}$ & $* *$ \\
\hline Arschgesicht & 46dub & 2.31 & - & - & - & - & - \\
\hline Arschloch & 29sub vs. 17dub & 2.17 & 1.98 & -2.333 & .020 & $\mathrm{n} / \mathrm{a}$ & $*$ \\
\hline $\begin{array}{l}\text { Leck mich (am } \\
\text { Arsch) }\end{array}$ & $32 \mathrm{dub}$ & - & 2.28 & - & - & - & - \\
\hline $\begin{array}{l}\text { Fick(en) vs } \\
\text { (ge)fick(t) }\end{array}$ & 48sub vs. 44dub & 2.42 & 2.35 & .857 & .391 & $\mathrm{n} / \mathrm{a}$ & NS \\
\hline Idiot & 8 sub & 1.80 & - & - & - & - & - \\
\hline (bloede) Kuh & 31dub & - & 1.46 & - & - & - & - \\
\hline Makkaroniziege & $34 d u b$ & - & 2.01 & - & - & - & - \\
\hline Mist & 30sub vs. 24dub & 1.31 & 1.16 & -2.826 & .005 & $\mathrm{n} / \mathrm{a}$ & $*$ \\
\hline \multirow[t]{4}{*}{ Mistkerl } & 6sub vs. 42sub & 1.45 & 1.61 & -1.670 & .095 & .0167 & NS \\
\hline & 6sub vs. 18dub & 1.45 & 1.51 & -.997 & .319 & .0167 & NS \\
\hline & 42 sub vs. $18 \mathrm{dub}$ & 1.61 & 1.53 & -1.121 & .262 & .0167 & NS \\
\hline & $6+42$ sub avg vs. $18 \mathrm{dub}$ & 1.53 & 1.53 & -.021 & .983 & $\mathrm{n} / \mathrm{a}$ & NS \\
\hline Nigger & 9sub vs. 43dub & 3.28 & 2.58 & -5.495 & .000 & $\mathrm{n} / \mathrm{a}$ & $* *$ \\
\hline Nutte & $38 \mathrm{dub}$ & - & 2.86 & - & - & - & - \\
\hline \multirow[t]{4}{*}{ Scheisse } & 15 sub vs. $12 \mathrm{dub}$ & 1.34 & 1.91 & -2.937 & .000 & .0167 & $* *$ \\
\hline & 15 sub vs. $20 \mathrm{dub}$ & 1.34 & 1.52 & -2.937 & .003 & .0167 & $*$ \\
\hline & 12dub vs. $20 \mathrm{dub}$ & 1.91 & 1.52 & -4.021 & .000 & .0167 & $* *$ \\
\hline & 15 sub vs. $12+20$ dub avg & 1.34 & 1.71 & -4.728 & .000 & $\mathrm{n} / \mathrm{a}$ & $* *$ \\
\hline scheissegal & 10dub & - & 1.70 & - & - & - & - \\
\hline \multirow[t]{4}{*}{ Schlampe } & 47sub vs. 35dub & 2.57 & 2.95 & -4.475 & .000 & .0167 & $* *$ \\
\hline & 47sub vs. 19dub & 2.57 & 2.84 & -3.305 & .001 & .0167 & $*$ \\
\hline & 19dub vs. 35dub & 2.84 & 2.95 & -1.704 & .088 & .0167 & NS \\
\hline & 47 sub vs. $19+35$ dub avg & 2.57 & 2.89 & -4.268 & .000 & $\mathrm{n} / \mathrm{a}$ & $* *$ \\
\hline Schwanz & $25 \mathrm{sub}$ & 2.07 & - & - & - & - & - \\
\hline Schwanzlutscher & $22 \mathrm{dub}$ & - & 2.65 & - & - & - & - \\
\hline \multirow[t]{4}{*}{ Schwein } & 7sub vs. 39sub & 2.17 & 1.85 & -2.879 & .004 & .0167 & $*$ \\
\hline & 7sub vs. 37dub & 2.17 & 1.92 & -2.197 & .028 & .0167 & NS \\
\hline & 39sub vs. 37dub & 1.85 & 1.92 & -.965 & .335 & .0167 & NS \\
\hline & $7+39$ sub avg vs. $37 \mathrm{dub}$ & 2.01 & 1.92 & -1.180 & .238 & $\mathrm{n} / \mathrm{a}$ & NS \\
\hline \multirow[t]{3}{*}{ schwul } & $13 \mathrm{dub}$ & - & 2.61 & - & - & - & - \\
\hline & $23 \mathrm{dub}$ & - & 2.22 & - & - & - & - \\
\hline & $13 \mathrm{dub}$ vs. $23 \mathrm{dub}$ & - & 2.42 & -4.057 & .000 & $\mathrm{n} / \mathrm{a}$ & $* *$ \\
\hline Tunte & $21 \mathrm{sub}$ & 2.34 & - & - & - & - & - \\
\hline Trottel & 26 sub & 1.55 & - & - & - & - & - \\
\hline \multirow[t]{7}{*}{ verdammt } & 16 sub vs. $28 \mathrm{sub}$ & 1.23 & 1.31 & -1.377 & .168 & .0083 & NS \\
\hline & 16sub vs. 40sub & 1.23 & 1.42 & -3.541 & .000 & .0083 & $* *$ \\
\hline & 16sub vs. 36dub & 1.23 & 1.50 & -3.998 & .000 & .0083 & $* *$ \\
\hline & 28 sub vs. 40 sub & 1.31 & 1.42 & -2.083 & .037 & .0083 & NS \\
\hline & 28sub vs. 36dub & 1.31 & 1.49 & -2.865 & .004 & .0083 & $*$ \\
\hline & 40sub vs. 36dub & 1.42 & 1.49 & -1.265 & .206 & .0083 & NS \\
\hline & $\begin{array}{l}\text { 16+28+40sub avg vs } \\
\text { 36dub }\end{array}$ & 1.32 & 1.49 & -3.359 & .001 & $\mathrm{n} / \mathrm{a}$ & $*$ \\
\hline Wichser & 45sub vs. 11dub & 2.50 & 2.65 & -1.72 & .085 & $\mathrm{n} / \mathrm{a}$ & NS \\
\hline
\end{tabular}

